\title{
O Mundo do Trabalho e Suas Representações na Literatura de Oswaldo França Jr
}

\author{
El Mundo del Trabajo y Sus Representaciones en la Literatura de Oswaldo \\ França $\mathrm{Jr}$
}
The World of Labor and Its Representation in literature of Oswaldo França $\mathrm{Jr}$

\author{
Carla Prado Lima Silveira Vilela ${ }^{1}$ \\ Angela Maria Rubel Fanini ${ }^{2}$ \\ Márcia dos Santos Lopes ${ }^{3}$
}

\begin{abstract}
Resumo
Este artigo analisa as construções discursivas sobre o mundo do trabalho no romance $\mathrm{O}$ homem de macacão (1972), de Oswaldo França Júnior. A literatura, como um celeiro de vozes que refletem e refratam situações do mundo da vida, traz enunciações que ecoam do mundo do trabalho, temática que abrange as relações humanas e passa, sobretudo, pela linguagem. Autor profícuo, vencedor do maior prêmio literário nacional em 1967, o mineiro França Júnior e sua obra ainda são pouco conhecidos no país. Suas composições fíccionais são permeadas de retratações das atividades produtivas cotidianas, da classe trabalhadora, da "gente do povo", descritos com uma agudeza ímpar. A obra em questão apresenta o cotidiano de Afonso, funcionário de oficina mecânica que realiza o desejo de infância de tornar-se proprietário de uma. É no ambiente da oficina que se projetam as diversas etapas da vida do mecânico, onde trabalho e vida pessoal se entrelaçam. No âmbito da linguagem e da literatura buscou-se lançar um olhar dialógico sobre o romance, partindo das contribuições de Bakhtin e o Círculo. Para o campo do trabalho, a pesquisa pautou-se nas reflexões de teóricos da tradição materialista histórica, que concebem o trabalho e seus sentidos segundo múltiplas significações. Assim, investigou-se como o escritor construiu a identidade das personagens trabalhadoras, como se deu a transposição do contexto extra-literário e sua formalização no discurso ficcional e o entrelaçamento do trabalho com a vida e as significações ontológicas da função laboral no cotidiano das personagens.
\end{abstract}

Palavras-chave: Literatura; Mundo do Trabalho; Discursos.

\section{Resumen}

Este artículo analiza las construcciones discursivas acerca del mundo del trabajo en la novela O homem de macacão (1972), de Oswaldo Francia Junior. La literatura, como un campo de voces que reflejan y refractan situaciones de la vida, presenta enunciaciones del mundo del trabajo, un tema que abarca las relaciones humanas y se desarrolla principalmente a través del lenguaje. Autor prolífico, ganador del más importante premio nacional de literatura en 1967, França Junior y su trabajo son aún poco conocidos en el país. Sus obras están llenas de representaciones del mundo del trabajo y de la clase obrera, narrados con gran destreza. La obra literaria $\mathrm{O}$ homem de macacão describe el cotidiano de Afonso, un empleado de una tienda de reparación de automóviles que lleva a cabo el deseo de la infancia de convertirse en propietario de su propia tienda. Es en el entorno de su

\footnotetext{
${ }^{1}$ Graduada em Letras Português / Inglês. Mestre em Tecnologia e Sociedade. Doutoranda em Tecnologia e Sociedade pela Universidade Tecnológica Federal do Paraná - UTFPR, pelo Programa de Pós-Graduação em Tecnologia. E-mail: carlaprado2000@gmail.com.

${ }^{2}$ Professora Doutora do Programa de Pós-Graduação em Tecnologia - PPGTE, da Universidade Tecnológica Federal do Paraná - UTFPR. Bolsista de Produtividade em Pesquisa, CNPq. E-mail: rubel@utfpr.edu.br.

${ }^{3}$ Professora da Universidade Tecnológica Federal do Paraná e doutoranda do Programa de Pós-Graduação em Tecnologia - PPGTE, da Universidade Tecnológica Federal do Paraná - UTFPR. E-mail: marcialopes_1@ @hotmail.com.
} 
tienda que tienen lugar las diferentes etapas de la vida del mecánico, donde el trabajo y la vida personal se entrelazan. Para analizar el campo del lenguaje y la literatura fueron adoptadas las reflexiones dialógicas de Bakhtin y el Círculo. Para analizar el campo del trabajo, la investigación se basa en las reflexiones teóricas de la tradición materialista histórica. Por lo tanto, se investigó cómo el escritor construye la identidad de las personajes trabajadoras, y también como ocurrió la implementación del contexto extra-literario y su formalización en el discurso de ficción.

Palabras claves: Literatura; Mundo del trabajo; Discursos.

\begin{abstract}
This paper consists of a discourse analysis of the labor world in the novel O homem de macacão, by Oswaldo França Junior. Literature is a field that reflects and refracts real-life situations, such as the voices of the world of labor. Although França Junior is a very talented writer, and to have won the greatest national literary prize in 1967, he and his works are still little known in the country. His novels are rich in representations of the world of labor. The novel O homem de macacão tells the day to day of Afonso, who was an employee of a machine shop, and later realizes the dream of childhood to have the own machine shop. Afonso's personal life is not separate from his work. It is in the machine shop that he lives, that he works, that he dates and that he relates to others. This research is theoretically founded - for the field of language and literature - on the concepts of Mikhail Bakhtin and the Circle, which enables the perception of certain artistic and compositional peculiarities in the novel structure from the dialogic matrix as a constitutive principle of all discourse. This research builds on the reflections on the labor world by thinkers of the historical materialist tradition. As a conclusion, we investigated how the writer constructed the identity of the characters who work. We also analyze how the extra-literary context is translated into the novel, and what are the ontological meanings of the work in the characters' lives.
\end{abstract}

Keywords: Literature; Labor World; Discourses.

\title{
1. Introdução
}

Longe de qualquer dogmatismo em querer precisar o conceito de trabalho no limiar de fronteiras fechadas, este artigo propõe-se a refletir sobre a criação verbal humana e de como são representadas as produções materiais da vida na arte literária, em uma atitude de problematização ${ }^{4}$. O fio que costura este texto, portanto, pauta-se em uma abordagem dialógica para analisar os discursos sobre o trabalho no romance $O$ homem de macacão (1984), de Oswaldo França Júnior, buscando investigar e atribuir significações às vozes sobre o mundo do trabalho no romance adotado.

As atividades materiais da vida são concebidas pela tradição marxista, grosso modo, como elementos da infraestrutura, enquanto que o universo das produções espirituais (bens não materiais produzidos pelo homem, como a política, a religião ou o Direito) caracteriza a superestrutura. Nesse ínterim, dialogando com o Círculo Russo protagonizado por Mikhail Bakhtin (2010, 2003, 2010b), advoga-se que não há uma separação muito nítida à tradicional dicotomia infraestrutura e superestrutura, uma vez que ambas formalizam o contexto

\footnotetext{
${ }^{4}$ Investigar o mundo do trabalho no campo literário é uma das temáticas desenvolvidas pelo Grupo de Pesquisa "Discursos sobre trabalho, tecnologia e identidades", da Linha de Pesquisa "Representação discursiva do universo da tecnologia e do trabalho em textos literários e de comunicação", do CNPq e do Programa de PósGraduação em Tecnologia - PPGTE - da Universidade Tecnológica Federal do Paraná - UTFPR.
} 
ideológico que acontece no mundo da vida, em relação recíproca. O campo da linguagem, por exemplo, perpassa as ideologias oficiais e as cotidianas, em uma movimentação dialógica ininterrupta, nem causal e nem determinista. Há, portanto, a impossibilidade da existência de uma dimensão sem a outra, pois o conjunto ideológico que se faz presente nas relações sociais encontra-se em ininterrupto movimento e em relação permanente.

O discurso dialógico, assim, caracteriza-se como uma produção ilimitada, uma vez que o elemento humano encontra-se em um ambiente de perguntas e respostas que se multiplicam ad infinitum. Em consonância com o Círculo Russo, não há dialogismo absoluto, assim como também não há uma integralidade monológica nos textos. Seguir a abordagem que aqui se propõe constitui-se uma via de investigação na qual se leva em conta a palavra do outro no discurso pelo olhar do pesquisador, cujo posicionamento axiológico não pode ser acobertado. Não há enunciação em que não haja um interlocutor, pois o sujeito fala e produz textos, os quais são respostas a enunciações outrora realizadas. Há, portanto, sempre uma presença outra no discurso, a qual pode ser estranha ou familiar à voz do locutor, e a obra romanesca, como um microcosmo da vida e a expressão máxima da cultura e do homem sobre si, é um celeiro fértil para averiguar essas representações.

Enquadrar o romance em estruturas preestabelecidas constitui-se em uma impossibilidade, uma vez que suas formas e fronteiras nunca se fixam, mas são forjadas pelo sujeito dialógico, cultural e historicamente situado, e representam o processo da vida humana, com seus labirintos de possibilidades, seu hibridismo e sua ambiguidade inerente. Toda produção literária, como material enunciativo, está atrelada a processos externos, elementos histórico-sociais e culturais, estabelecendo uma relação com a sociedade onde surge, o que justifica o caráter coletivo de uma obra. Afirma o autor russo que "A obra é viva e significante do ponto de vista cognitivo, social, político, econômico e religioso num mundo também vivo e significante" (BAKHTIN, 2010a, p.30). Como elemento vivo e orgânico, a obra está vinculada às dimensões espaço-temporais que permeiam a história humana, comunicando-se com realidades concretas e culturais de uma ou mais épocas.

Nessa perspectiva entende-se que a produção literária possibilita um dialogar ideológico e/ou contraditório com ela própria, com o autor e com nós mesmos, sujeitos do discurso. Assevera Bakhtin (2003, p.118) que "No acontecimento singular e único da existência, é impossível ser neutro". A posição exotópica em que se encontra o pesquisador, atribuindo significações ao objeto estético de uma certa distância, e refratado pelo seu olhar e pela cultura em que está inserido, é a posição que permite a realização do trabalho estético. Reflexão desse tipo nos conduz a uma dimensão ética, uma vez que não podemos conceber o 
agir teórico discursivo em cisão com o agir concreto dos sujeitos. O sujeito é agente no social do mundo da vida, e o dialogismo, enquanto princípio geral do agir, está fundamentado na irrepetibilidade dos atos humanos na concretude da realidade. Passemos, então, a refletir sobre o autor em análise e o seu romance.

\section{Oswaldo França Jr e o romance $O$ homem de macacão}

Com uma trajetória de vida profissional bastante eclética, Oswaldo França Júnior (1936-1989) foi militar, corretor de imóveis, vendedor de carros usados, gerente de empresa de ônibus, proprietário de banca de revistas, dentre outras funções. Entre a produção de contos e textos esparsos, passa a dedicar-se à literatura, sobretudo ao romance, a partir dos anos 1960, com abundante produção literária ${ }^{5}$. Observa Lafetá (2004, p.251-252), sobre a obra do autor mineiro:

Há, portanto, uma valorização do trabalho, coisa rara numa literatura que quase sempre o desprezou e evitou representá-lo, que glorificou o malandro e, quando mostrou o trabalhador foi para exibir a exploração de que ele é vítima e combater politicamente a sua opressão.

Lançando seu olhar para o mundo do trabalho, França Jr representa em seus textos o inacabamento de um cotidiano que se mantém sempre em processo, com os fatos corriqueiros que diariamente acontecem nos grandes centros urbanos, permeado de intempéries e pluralidade de ações. O brasileiro trabalhador é o herói da labuta e França Jr romanceia o labirinto de vozes que essa atividade suscita: "Seus treze romances focalizam, de vários ângulos e em vários estilos, o ser humano na faina do ganha-pão. Para o autor, não o ser extraordinário, mas o assalariado é o herói autêntico de nossos dias" (LOPES, 2010, p.219). Por um lado, aparecem as injustiças, as lutas e dificuldade desse trabalhador que sai cedo de casa para "pegar no pesado", que enfrenta trânsito, filas, mau tempo para realizar sua atividade laboral diária. Por outro, vê-se o sentimento de valoração e dignidade pela atividade exercida, o prazer da exaustão de um dia produtivo e os laços de afetividade que se constroem em conjunto no ambiente laboral. Essas problematizações do mundo do trabalho e do espaço urbano, como retratação das mudanças trazidas pela modernidade e as variações da sociedade contemporânea, são também percebidas com clareza nas obras de escritores do tempo

\footnotetext{
${ }^{5}$ Um de seus romances mais conhecidos, e que o consagrou, é Jorge, um brasileiro, obra que inspirou o seriado global Carga Pesada, de 1979. Com essa obra França Jr vence o principal concurso literário do país à época, o Walmap, em 1967.
} 
presente, como Luiz Ruffato, Roniwalter Jatobá, Bernardo Carvalho, Paulo Lins, Rubem Fonseca, dentre outros.

França Jr, contudo, foi relativamente inédito ao protagonizar em seus romances um caminhoneiro (Jorge, um brasileiro, 1967), um jovem engenheiro (Um dia no Rio, 1969) e um mecânico de oficina de carros (O homem de macacão, 1972), por exemplo. A narrativa do romance em análise flui em tom rápido e vernacular, que remete à informalidade das tradições orais. O cotidiano dos mecânicos de uma simples oficina de bairro é retirado do anonimato e posto em palco, apresentando características curiosas e ao mesmo tempo emblemáticas do dia a dia nesse ambiente de trabalho. Há abundância de detalhes das funções e dos serviços executados pelos trabalhadores, além da ênfase em um imaginário social já bastante cristalizado pelo trabalhador de oficinas: galanteador, briguento, malandro, viril, às vezes preguiçoso. Além dessa visão mais informal, caótica e permeada de vícios humanos, percebese uma outra, a qual se evidencia como racional, lucrativa, metódica representada pelo anseio do protagonista em controlar, organizar e racionalizar a oficina mecânica da qual se tornou proprietário.

Afonso, o protagonista, principia explicando a um corretor de imóveis que quer comprar sua oficina os motivos de não querer vendê-la. Nessa conversa conta fatos de sua vida, marcada por idealizações, aventuras amorosas e pelo trabalho. Em cada episódio que revela aparece juntamente a história das mulheres que marcaram sua vida: a mocinha inexperiente Maria José, que o paquerava na época em que alugava uma oficina na Avenida Francisco Sá, em Belo Horizonte; a amargurada dona de casa Maria da Paz, com quem morou junto por um ano e meio, quando alugava um galpão em Bela Vista; a organizada e eficiente Júlia, secretária de Afonso na oficina que comprou; a loura da loja de anúncios, para quem Afonso dirigia suas cantadas todas as vezes que ia até o local publicar algum material.

Entre uma história e outra, há uma miscelânea de trabalhadores que preenchem as páginas do romance e também a retratação de um emaranhado de locais de ofício, em movimento quase contínuo. Quando trabalhou como aprendiz em uma oficina na cidade de Betim, MG, Afonso aprendeu as técnicas e alugou um galpão em sociedade com o eletricista Francisco Rita, com foco em mecânica e lanternagem. Expulso ele e o sócio da cidade, em razão de uma peripécia de Rita, Afonso aluga um pequeno espaço no fundo de uma vila, em Belo Horizonte. Enéas, seu amigo de longa data, insistia para que Afonso comprasse a oficina mecânica da qual Enéas e o primo João Flório eram sócios. Os dois queriam se livrar da oficina, pois diziam que ela só lhes trazia problemas e confusão. Relutante no início, por não 
ter reservas financeiras, Afonso acaba aceitando a proposta em razão de poder adquirir a oficina que tanto sonhara com prazo de três anos para pagar e sem entrada.

Então proprietário, Afonso tenta organizar o ambiente de trabalho, a parte burocrática, a relação das peças e o quadro de funcionários, que outrora "era tudo desorganizado e sem controle”. A racionalização se aprofunda quando contrata a secretária Júlia, com quem posteriormente teve um breve romance. A moça era eficiente e organizada, características que o mecânico gostava de enfatizar. O desejo de ordem e controle de Afonso contrastava com os vícios e conflitos humanos dos funcionários da oficina. Seu Valdelino Moreira, o Zé Golo, por exemplo, era um dos mecânicos mais antigos da casa, que ora ou outra arrumava confusão por causa do alcoolismo. Solitário, quando ficou hospitalizado em razão de uma briga, não havia ninguém para se responsabilizar por ele ou alimentar os animais, seus únicos companheiros. Por caridade, Afonso cumpriu essa função, pois o único contato do mecânico era o do ambiente de trabalho.

A centralidade do romance de França Jr, portanto, são as relações humanas conflituosas dentro e fora do trabalho, relações que principiam em tom de conversa informal e assim terminam, com suas contradições e conflitos, remetendo às reflexões e refrações da vida extraliterária. Não se vê separação rígida entre a intimidade do ambiente privado, o lazer e o trabalho. Pelos discursos das personagens, há construções suficientes sobre o mundo do trabalho a serem problematizadas, sobretudo no que se refere à racionalização do mundo laboral em conexão com a ausência de controle da vida doméstica. Vejamos agora as significações do trabalho na vida de alguns personagens.

\subsection{O mundo do trabalho no romance e suas particularidades}

Desde o título da obra, que se refere à indumentária masculina do trabalhador de oficina mecânica, geralmente feita de tecido de brim bastante reforçado, para sobreviver à labuta desgastante e manual executada nesse ambiente, o trabalho é construto fundamental nesse romance aparentemente singelo, mas que traz a palco diferentes inquietudes.

Ao presenciar o cotidiano caótico na oficina dos amigos Enéas e João Flório, Afonso idealiza um tipo de oficina em que práticas humanas de pessoalidade não se façam presentes no ambiente de trabalho, além de buscar com afinco a racionalização da parte burocrática do escritório:

De fora não dava para ver que aqui dentro era tudo desorganizado e sem controle, como eu sabia que era. Dava para desconfiar, se a gente prestasse atenção, porque o pessoal entrava e saía sem dar confiança a ninguém. Parecia um lugar onde o dono 
não estava. No portão havia sempre aquela rodinha de gente conversando. Os fregueses traziam os carros e iam entrando, e eles mesmos procurando os mecânicos, tratando os serviços. Eu criticava Enéas e João Flório por terem deixado a coisa chegar àquele ponto. E não sentia medo de que acontecesse o mesmo comigo. Comigo não, falava. (FRANÇA JR, 1982, p.43).

Nesse contexto destaca-se João Flório. Mecânico encarregado da parte de pintura e lanternagem, o personagem não era muito afeito ao trabalho ou ao cumprimento de responsabilidades. Representa paradigma sobre o mundo laboral avesso ao defendido pelo protagonista e, em partes, por Enéas, seu sócio. Não possuía o mesmo ímpeto que Enéas em vender a oficina, pois nos cinco anos que ali trabalhou formalizou sua identidade e consolidou amizades: "Eu não faço questão nenhuma de vender. Não preciso de descanso e gosto daqui. Se a gente vender, não vai ser por minha causa, será por vontade sua, porque você quer" (FRANÇA JR, 1982, p.47). Prezava mais pelos relacionamentos com os colegas, pelos batepapos descontraídos entre uma tarefa e outra, a exercer um trabalho sem distrações e visando lucros. Assim Afonso confere acabamento à personagem:

João Flório era o encarregado da parte de pintura e lanternagem. Mas ele não ligava para nada. O que ele entende e gosta é de contar piadas e agradar aos outros. Passava o dia conversando com os mecânicos e jogando porrinha para ver quem pagava os cafezinhos. Todas as vezes que eu vinha aqui, ele estava no bar, aí do lado. Ficava mais tempo no bar tomando café e conversando, do que na oficina. Quando me via, gritava de longe: - Afonso, meu amigo - E me abraçava. (FRANÇA JR, 1982, p.43)

Flório contraria a lógica de trabalho linear defendida por Afonso e seu sócio, Enéas. Estava sempre tratando bem aos outros, e consolando os mecânicos que se chateavam com as grosserias de Enéas. A centralidade é o lazer, e não o trabalho, o que em certa medida, remete ao manifesto de Lafargue (2016, [1880]), que responde sarcasticamente à sociedade de sua época “obcecada pelo labor". De forma irônica, o autor cubano propõe jornada de trabalho de não mais do que três horas diárias, para que se possa aproveitar o tempo livre vivenciando a preguiça e o deleite de atividades paralelas. Ou, no caso de João Flório, contar piadas, agradar aos outros, jogar porrinha, tomar cafezinhos e cerveja no horário do expediente.

Por outro lado, percebe-se que nem toda adulação de Flório para com os mecânicos é gratuita. Mesmo Afonso julgando conceber o todo da personagem, dando-lhe acabamento em tom monológico, escapam-lhe outros matizes transgredientes à sua consciência: o papel que Flório desempenha em alguns momentos é de contenção de conflitos e manutenção do trabalho. As conversas aparentemente "jogadas fora" com alguns mecânicos são uma espécie de negociação e preservação dos laços entre patrão e funcionários, que garantem não só o convívio social entre ambos, mas também a permanência docilizada dos quatro mecânicos 
que aceitaram condições de trabalho fora da legislação trabalhista. E tudo na base da confiança e da camaradagem. Há, portanto, uma certa relação de exploração entre João Flório e alguns mecânicos, mas não nos marcos mesquinhos e capitalistas, que só visam lucros. O mecânico gosta das relações sociais com os empregados, e seu perfil é mais afetivo, atrapalhado e conversativo, menos preocupado com lucros e eficiência.

Já para Afonso, o trabalho é o eixo seguro em torno do qual se formaliza a sua identidade e seu projeto de vida. Como artífice empreendedor, encarna o homo faber que labuta e "fabrica" teleológicamente as condições que lhe propiciam a manutenção da vida. Em paralelo ao seu desejo e ímpeto de ordenamento e controle das situações, vê-se certa desordem e falta de controle em sua vida pessoal, que se aproxima do tipo de oficina caótica que critica constantemente. Percebe-se uma relação contraditória entre o narrador ficcional e estilizado artisticamente e o autor, relação essa que formaliza a arquitetônica literária erigida ética e esteticamente pelo autor. $\mathrm{O}$ ambiente-espaço de oficina mecânica e seu cotidiano laboral permeado de informalidades podem ser entendidos como espaço privilegiado das próprias relações humanas conflituosas, não raro exploratórias, e nem sempre com explicações definidas.

Já proprietário da oficina mecânica que tanto desejara, Afonso corrobora a máxima de que quando há mudança de gerência, há demissões. Enxugou o quadro de funcionários, demitindo os aprendizes e permanecendo apenas com alguns tarefeiros e os quatro mecânicos que não podiam ser demitidos, em razão de a oficina estar dívidas com o INPS:

Combino a coisa por tarefa. Quando terminam, vão embora. Quando preciso deles, mando um recado, porque esses que trabalham direito estão sempre passando por aqui. Se eu não tivesse que ficar com estes quatro, acho que não teria nenhum contratado. Nenhum de carteira assinada. Não posso fechar a carteira destes porque, porque não coloquei ainda o INPS em dia. (FRANÇA JR, 1984, p.78).

Afonso sabe que não é possível exercer o seu trabalho de modo solitário, que o outro é necessário. Mas esse outro, contudo, é visto de forma utilitarista, como pode ser conferido pelo discurso do patrão sobre os tarefeiros. Prefere pagar por serviços realizados à parte, por cada especialidade da mecânica: lataria, lanternagem, elétrica, motorização. Vê-se aí o ideal racionalizador de Afonso de forma mais direta, voltado aos lucros e à eficiência. Os tarefeiros de sua oficina são indivíduos sem trabalho fixo, que se movimentam de oficina em oficina em busca de serviços executados a soldo, para que possam ganhar alguns trocados. Isso nos remete à Sennet (1999) que faz uma análise do trabalho flexível e móvel, que culmina em trabalhadores sem ponto fixo e sem uma narrativa humana e social que possibilite a 
construção identitária de si. Nesse quadro, os tarefeiros não se reconhecem como classe, visto que sua atuação no mundo do trabalho é móvel e volátil, não permitindo um aprendizado contínuo. Eles se constituem como usufruto do patrão, quando este tem necessidade dessa mão de obra, uma vez que não quer a responsabilização e as despesas da formalidade trabalhista.

Seguindo o ideal de uma oficina racionalizada e que visa à disciplinarização dos comportamentos desviantes, onde a organização quase absoluta e o serviço especializado possam habitar, Afonso contrata uma secretária, Júlia. A moça é descrita como eficiente, organizada, de poucas palavras e com a feição preocupada:

Percebi como Júlia era eficiente no trabalho quando comecei a comparar o que era o escritório na época do rapazinho e depois, quando ela estava aqui. O rapaz não organizava nada. Os papéis ficavam com cima do cofre, caindo pelo chão, sujandose e perdendo. E ele não resolvia coisa nenhuma. Tudo tinha que me perguntar. Júlia, até os orçamentos ela preparava sozinha. Quando chegava perto de mim, era já para eu assinar. Quando deixou de ser secretária, continuou mantendo tudo organizado quase que sozinha (FRANÇA JR, 1982, p.89).

Ao contratá-la, Afonso conseguiu, em partes, diminuir a pessoalidade do lugar e aumentar a racionalização da parte burocrática. É no trabalho que Júlia pode exercer o seu processo criativo e receber elogios do patrão:

Ela organizou tudo. Montou o arquivo, arranjou as pastas. Mudou o escritório. Meus acertos com os mecânicos e com os fregueses, que levavam muito tempo, passaram a ser feitos em poucos minutos. As listas dos serviços realizados, das peças trocadas, das tintas consumidas, tudo estava sempre em dia. Até dinheiro trocado para facilitar os acertos ela providenciava. Quando se dirigia aos mecânicos, eles a ouviam com a máxima atenção. E obedeciam as ordens dela (FRANÇA JR, 1982, p. 90-91).

Afonso fazia o possível para separar a vida pessoal dos trabalhadores do ambiente de trabalho e exercer o controle sobre tudo. Mas como entre trabalho e vida não há fronteiras, o mecânico acabava sempre envolvido nos problemas pessoais de seus funcionários, o que aconteceu com Júlia, quando passou a namorá-la e culminou com a sua saída da oficina.

O desejo de dominação e de impessoalidade no trabalho escapa às mãos de Afonso, como no caso do mecânico Zé Golo. Seu Valdelino Moreira, o Zé Golo, era um dos quatro mecânicos efetivos. Alcoólatra, muitas vezes chegava embriagado para realizar os serviços, o que irritava Afonso, que o dispensava toda vez que chegava nessas condições. Certa feita provoca uma desavença na rua por estar alcoolizado, o que culmina com sua hospitalização. A ruptura que ocorre entre esse trabalhador e seu trabalho na oficina, nos dias em que ficou internado, causa uma certa fragilidade em sua identidade de cidadão trabalhador. 
Zé Golo sente-se perdido, isolado e sem a companhia de seus animais, que tanto preza. Embora o ambiente, em que trabalha seja marcado pela transitoriedade e não lhe propicie perspectivas futuras, e nem lhe oportunize "realização plena", o trabalho é seu único meio de sobrevivência, o meio de sustentar seu vício e o que constitui a sua identidade e o livra da alcunha única de "alcoólatra". A inatividade, portanto, traz um contexto de humilhação para o empregado, que o impede de realizar-se como cidadão, afetando a sua dignidade. Seus animais complementam o sentido de sua existência. Ama a companhia dos bichos a ponto de levar cachorros e passarinhos para perto de si quando está na lida. Sua preocupação maior quando sofre o acidente é quem irá alimentá-los, atividade que Afonso desempenha por solidariedade pela condição do empregado.

Ao longo de grande parte da narrativa que o mecânico patrão relata ao corretor de imóveis, seu interlocutor, percebe-se a face racional e controladora de Afonso. Contudo, semelhantemente ao Deus Jano, representante das transitoriedades e das mudanças, há um duplo de Afonso. Em sucintos e significativos discursos, o mecânico mostra-se mais solidário com o coletivo, ao valorizar as amizades e um trato mais generoso com os que o cercam. Depreende-se desses discursos que não é unicamente a racionalidade ou as relações instrumentais que o movem, mas que para Afonso, os momentos de alegria da vida só se constroem com um "nós":

Na fazenda eu tinha ficado sozinho, e, à noite, pensava muito. (...). Mas quando voltei da fazenda, eu estava com disposição para aceitar até essas coisas dele. Cheguei querendo me encontrar com alguém conhecido. Alguém que eu pudesse ir a um bar, beber uma cerveja e conversar, com calma. Tanto é que fui chegando e convidando o Rita. (FRANÇA JR, 1984, p. 120).

Quando voltei para Betim estava com a ideia de conviver melhor com as pessoas. Brigar menos e ser mais tolerante com os erros dos outros. (...) Eu tinha visto um enterro e ele me havia feito pensar nas coisas da vida. E chegar à conclusão de que o certo era ter mais boa vontade para com os outros. (...) E olhava tudo tão deserto, e pensava que uma coisa que devia ser ruim é a pessoa fazer tão poucos amigos durante a vida que, quando morresse, não tivesse mais do que dois para carregar o caixão. (FRANÇA JR, 1984, p.121-122).

Quando está recluso em uma fazenda, onde foi realizar um serviço, Afonso percebe-se alijado dos outros, revelando a fragilidade volitivo-emocional da personagem. A solidão, como um interlocutor a acentuar o seu vazio, fez com que, por um breve instante, o protagonista vislumbrasse a imagens externa de sua vida e se percebesse afetivamente desamparado. Recorda alguns amigos, como o Francisco Rita, quem está sempre criticando por não desempenhar o trabalho da forma como ele gostaria, e medita no valor e na importância da afetividade. Foi preciso afastar-se da rotina de trabalho e do ambiente no qual 
está diuturnamente em contato com o outro para que pudesse dar-se conta de que o peso emocional da vida humana sustenta-se no outro.

Situação semelhante de introspecção, que o instiga a um pensar mais solidário, é quando visualiza um enterro, em que havia apenas dois homens conduzindo o caixão. Nessa situação, Afonso faz uma autocritica e pensa na própria intolerância e na dureza com que trata os outros. Ao deparar-se com o acabamento do elemento humano, representado pela morte, o mecânico visualiza que sua vida ainda está em processo e que sua jornada não se limita ao trabalho ferrenho e racionalizado, mas também no bom relacionamento com as pessoas e no legado que se deixa nessa vida e constitui os indivíduos em humanos.

$\mathrm{Na}$ rotina mediada pelo trabalho, os conflitos das mais diversas naturezas podem aparecer, podem mudar planos, frustrar ambições laborais ou conformar. Contudo, é substancial a presença do outro para completá-la de seu vazio, da mesma forma, como exemplifica Bakhtin (2003), é necessário o outro para expiar meus pecados, pois de dentro de mim mesmo eu não posso me absolver. Assim, o discurso no romance em análise se realiza todo nas fronteiras inacabáveis de uma enunciação a outra. Sua dialogia é perene, pois nunca se encerra no ponto final de um dizer, porque o discurso no romance simula o sentido, o espaço e o tempo da vida extraliterária.

\section{Referências}

ALBORNOZ, S. O que é trabalho. São Paulo: Brasiliense, 1986.

BAKHTIN, M. O problema do conteúdo, do material e da forma na criação literária. In: Questões de literatura e de estética: a teoria do romance. São Paulo: Hucitec, 2010a.

2003.

. Estética da criação verbal. 4. ed. Trad.: Paulo Bezerra. São Paulo: Martins Fontes,

. Para uma filosofia do ato. Tradução inédita [para fins didáticos] de Carlos Alberto Faraco e Cristóvão Tezza da edição americana Toward a Philosophy of the act (Austin: University of Texas Press, 1993).

. Problemas da poética de Dostoiévski. 5 ed. Trad.: Paulo Bezerra. Rio de Janeiro: Forense, 2010b.

; VOLOSHINOV, V. Marxismo e Filosofia da linguagem. Trad. Michel Lahud e Yara Frateschi Vieira. São Paulo: Hucitec, 2010.

FRANÇA JR, O. O homem de macacão. Rio de Janeiro: Nova Fronteira, 1984.

FARACO, C. A. Linguagem e diálogo: as ideias linguísticas do círculo de Bakhtin. São Paulo: Parábola, 2009. 
LAFARGUE, P. $O$ direito à preguiça. E-books Brasil. Disponível em: <http://www.ebooksbrasil.org/adobeebook/direitopreguica.pdf> Acesso em: 15 julho de 2016.

LAFETÁ, J. L. O romance atual: considerações sobre Oswaldo França Júnior, Rui Mourão e Ivan Ângelo. In: A dimensão da noite. São Paulo: Duas cidades, 2004. (p.241-264).

LOPES, M. A. G. O voo certeiro: a novelística de Oswaldo França Júnior. Rio de Janeiro: Sete Letras, 2010.

SUPLEMENTO LITERÁRIO: Lembranças de Oswaldo França Júnior. Belo Horizonte, Outubro/2009. Edição Especial. Secretaria de Estado de Cultura de Minas Gerais, MG.

SENNET, R. A corrosão do caráter: consequências pessoais do trabalho no novo capitalismo. Trad.: Marcos Santarrita. Rio de Janeiro: Record, 1999. 